\title{
An Empirical Analysis of US Interest Rate Swap Spreads during the Sovereign Crisis of the Euro Zone
}

Takayasu Ito

\author{
Niigata University, Faculty of Economics \\ E-mail address: tito@econ.niigata-u.ac.jp
}

\section{Doi:10.5901/mjss.2013.v4n10p198}

\begin{abstract}
This paper analyzes US interest rate swap spreads in relation to the sovereign crisis of the Euro zone. The results reveal that swap spreads of 5- and 10-years incorporate default risk positively in accordance with the theory. According to Ito (2010) which analyzed the period of global financial crisis stemming from subprime loan problem in the US, the default risk is negatively incorporated in the period of financial crisis stemming from US sub-prime loan. This is mainly due to the difference of magnitude of the two crises. The impact of the sovereign crisis of the Euro zone was not as great as the previous crisis. On the other hand, the impacts of slope, TED spread, and volatility are similar to Ito (2010). Steeper yield curve causes narrower swap spreads in swap spreads of 2- and 10-year. When liquidity gets tighter in money market, swap spreads of 2- and 5-year get wider. The size of impact is larger in 2-year swap spread. Higher volatility causes the widening of swap spreads in 5- and 10year. This is mainly because the market participants were uncertain as for the future of monetary policy by the FRB.
\end{abstract}

Keywords: Default Risk, Liquidity Premium, Monetary Policy, Sovereign Crisis of Euro Zone, Swap Spread

\section{Introduction}

An interest rate swap is an agreement between two parties to exchange cash flows in the future. In a typical agreement, two counterparties exchange streams of fixed and floating interest rate payments. A fixed interest rate payment can thus be transformed into a floating payment and vice versa. The amount of each floating rate payment is based on a variable rate that has been mutually agreed upon by both counterparties. For example, the floating rate payment could be based on 6-month LIBOR (London Interbank Offered Rate). The market for interest rate swaps grew exponentially in the 1990's. According to a survey by BIS (Bank for International Settlements), the notional outstanding volume of interest rate swap amounted to US $\$ 379,401$ billions at the end of June $2012^{1}$. Differences between swap rates and government bond yields of the same maturity are referred to as swap spreads. If the swap and government bond markets are efficiently priced, swap spreads usually reveal something about the perception of the systemic risk in the banking sector.

As Ito (2010) mentions, US swap spreads in the period of financial crisis from February 8, 2007 through March 12, 2009 did not incorporate default risk positively. Swap spreads became negative. Usually, swap rates are supposed to be higher than government bond yields. The function of price discovery in the market was lowered because of liquidity shortage caused by financial shocks, such as that experienced by BNP Paribas shock in August, 2007 and the collapse of Lehman Brothers in September, 2008.

This paper analyzes US interest rate swap spreads in the market turmoil during the sovereign crisis of the Euro zone. Government bond markets in several countries started to experience severe stress in the first half of 2011. Massive sell-offs were observed especially in Greek government bonds. At the same time, the CDS (Credit Default Swap) premium for Greek bonds jumped dramatically. This triggered the rises in government bond yields and CDS premiums in countries such as Italy, Spain and Portugal. The impact of the crisis spread to other markets in the form of declining stock prices and higher government bond yields. The contribution of this paper can be described as follows. This is the first paper to analyze US interest rate swap spreads in relation to the sovereign crisis of the Euro zone.

The remainder of this paper is as follows. Section 2 provides the literature review. Section 3 discusses the determinants of swap spread. Section 4 describes the data and provides summary statistics. Section 5 presents the framework of the analysis and the results. Section 6 concludes.

${ }^{1}$ Statistics are cited from Semiannual OTC derivatives statistics for the end of June 2012. For details, see Bank for International Settlements (2012). 


\section{Literature Review}

Sun et al (1993) examine the effect of dealers' credit reputations on swap quotations and bid-offer spreads by using quotations from two interest rate swap dealers with different credit ratings (AAA and A). The AAA offer rates are significantly higher than the A offer rates, and the AAA bid rates are significantly lower than the A bid rates. They also document the relation between swap rates and par bond yields estimated from LIBOR and bid rate (LIBID) data. They identify some of the problems in testing the implications of swap pricing theory.

Duffie and Huang (1996) present a model for valuing claims subject to default by both contracting parties, such as swaps and forwards. With counterparties of different default risk, the promised cash flows of a swap are discounted by a switching discount rate that, at any given state and time, is equal to the discount rate of the counterparty for whom the swap is currently out of the money (that is, a liability). The impact of credit-risk asymmetry and netting is presented through both theory and numerical examples, which include interest rate and currency swaps.

Brown et al (1994) analyze US swap spreads to find that 1) short- term, 1-, and 3-year swaps are priced differently from longer-term, 5-, 7-, and 10-year swaps; and 2) the pricing dynamics for all five swap maturities changed substantially during the period spanning January 1985 to May 1991. Cossin and Pirotte (1997) conduct empirical analysis on transaction data and show support for the presence of credit risk in swap spreads. Credit ratings appear to be a significant factor affecting swap spreads, not only for their pooled sample but also for IRS and for CS separately. In IRS, the credit rating impact on prices seems to be largely to the detriment of the non-rated companies.

Lang et al (1998) argue that an interest rate swap, as a non-redundant security, creates surplus which will be shared by swap counterparties to compensate their risks in swaps. Analyzing the time series impacts of swap counterparties' changes of risks on swap spreads, they conclude that both lower and higher rating bond spreads have positive impacts on swap spreads. Lekkos and Milas (2001) assess the ability of the factors proposed in previous research to account for the stochastic evolution of the term structure of U.S. and U.K. swap spreads. Using as factor proxies the level, volatility, and slope of the zerocoupon government yield curve as well as the Treasury-Bill-LIBOR spread and the corporate bond spread, they identify a procyclical behavior for the short-maturity US swap spreads and a countercyclical behavior for longer maturity US swap spreads. Liquidity and corporate bond spreads are also significant, but their importance varies with maturity.

Minton (1997) directly tests the analogy between short-term swaps and Eurodollar strips and finds that fair-value short-term swap rates exist in the Eurodollar future market. However, proxies for differential probability of counterparty default are statistically significant determinants of the difference between OTC swap rates and swap rates derived from Eurodollar futures prices for maturities of 3 and 4 years.

Fehle (2003) analyzes 2- year and 5-year swap spreads in seven countries (the US, the UK, Japan, Germany, France, Spain and the Netherland), concluding that corporate bond spread, LIBOR spread and the slope of the yield curve are components of swap spreads.

Huang and Chen (2007) analyze the asymmetric impacts of various economic shocks on swap spreads under distinct Fed monetary policy regimes. The results indicate that (a) during periods of aggressive interest rate reductions, the slope of the Treasury term structure accounts for a sizeable share of the swap spread variance although default shock is also a major player; (b) on the other hand, liquidity premium is the only contributor to the 2-year swap spread variance in monetary tightening cycles; (c) the impact of default risk varies across both monetary cycles and swap maturities; (d) the effect of interest rate volatility is generally more evident in loosening monetary regimes.

Ito (2010) analyzes the impacts of financial crises on interest rate swap spreads by dividing the whole sample period into two. The first period covers a relatively calm market; the second period covers the financial crisis. The default risk is negatively incorporated in the period of financial crisis. The slope is positively incorporated in short- and long- term maturities in the period of financial crisis. The liquidity premium is positively incorporated only in short term maturity in the period of financial crisis. The volatility is a positive determinant of US swap spreads in the period of financial crisis.

\section{Determinants of Swap Spread}

\subsection{Liquidity Premium}

During periods of weak economy, treasury bonds are considered to be more liquid, and swaps thus command a larger liquidity premium. The liquidity effect may be absent in the aggregate data, but can arguably be pronounced under certain market conditions. Minton (1997), Brown et al (1994) and Lekkos and Milas (2001) check the influence of TED (T- 
bill Euro Dollar) spread. First, a case in which the floating rate and fixed rate are swapped based on the yield curve of government bond is described in equation (1):

$$
\frac{f_{1}}{\left(1+R_{1}\right)}+\frac{E\left(f_{2}\right)}{\left(1+R_{2}\right)^{2}}+\cdots+\frac{E\left(f_{n}\right)}{\left(1+R_{n}\right)^{n}}=\frac{C}{\left(1+R_{1}\right)}+\frac{C}{\left(1+R_{2}\right)^{2}}+\cdots+\frac{C}{\left(1+R_{n}\right)^{n}}
$$

$E\left(\right.$ ) is an operator indicating expectation, $\mathrm{C}$ is a coupon, $f_{n}$ is a floating rate, $R_{n}$ is a fixed rate of government bond.

In equation (1), the floating rate and fixed rate are swapped on the condition that there is no default risk. Present values of both floating rate and fixed rate become equal. Here exchange of cash flows is presupposed to happen once a year.

In the case of swap transactions, the floating rate is the Euro dollar, for example, LIBOR which is usually higher than short-term government bills. Thus fixed side results in higher rates. Here the difference between the Euro- dollar rate, for example, LIBOR and the short-term TB (Treasury- Bill) rate is defined as TED spread. Swap rate and TED spread are ralated as described in equation (2):

$$
\begin{aligned}
& \frac{f_{1}+T E D_{1}}{\left(1+R_{1}\right)}+\frac{E\left(f_{2}+T E D_{2}\right)}{\left(1+R_{2}\right)^{2}}+\cdots+\frac{E\left(f_{n}+T E D_{n}\right)}{\left(1+R_{n}\right)^{n}}=\frac{C+S S}{\left(1+R_{1}\right)}+\frac{C+S S}{\left(1+R_{2}\right)^{2}}+\cdots+\frac{C+S S}{\left(1+R_{n}\right)^{n}} \\
& T E D_{n} \text { is TED spread, SS is swap spread. }
\end{aligned}
$$

Equation (2) can be rewritten into equation (3) to show that swap spread is a weighted average of present and future TED spreads.

$$
\frac{T E D_{1}}{\left(1+R_{1}\right)}+\frac{E\left(T E D_{2}\right)}{\left(1+R_{2}\right)^{2}}+\cdots+\frac{E\left(T E D_{n}\right)}{\left(1+R_{n}\right)^{n}}=S S\left(\frac{1}{\left(1+R_{1}\right)}+\frac{1}{\left(1+R_{2}\right)^{2}}+\cdots+\frac{1}{\left(1+R_{n}\right)^{n}}\right)
$$

In addition to liquidity premium, default risk, slope of yield curve and volatility have been considered determinants of interest rate swap spread in previous studies.

\subsection{Default Risk}

According to Minton (1997), Brown et al (1994), and Lekkos and Milas (2001), the default risk in swaps can be proxied with the information from the corporate bond market. Any such proxy is imperfect, as notes in previous studies, because the characteristics of swaps and corporate bonds are not entirely comparable. Nevertheless, because swap default spreads are unobservable, the difference between the yield on a portfolio of corporate bonds and the yield on an equivalent government bond can be used as a proxy for the default premium.

\subsection{Slope of Yield Curve and Volatility}

Following the Sorensen and Bollier's (1994) framework, in which the slope of the term structure and interest rate volatility determine the value of the option to default, these two variables are used. It is notable that the impacts of the yield curve and interest rate volatility on swap spreads may not be symmetrical under various market conditions.

According to Alworth (1993), the impact of the slope of the term structure on swap spreads could be either positive or negative. When the yield curve is upward sloping, the fixed payer (floating receiver) is exposed to higher counterparty risk due to higher default risk exposure associated with the higher future floating payments. A lower fixed swap rate will compensate for this increased risk. Swap spreads are thus expected to be negatively related to the slope of the term structure.

On the other hand, the expected default premium should be higher at a time of recession and financial instability. In this case, swap spreads are expected to be positively related to the slope of the term structure. Increasing interest rate volatility is often associated with economic uncertainty, as such, it is expected to positively influence swap spreads. Similarly, as Huang and Chen (2007) describe, swap spreads may be more responsive to the shape of yield curve during periods when it is steep due to the "flight to quality" concern. Huang and Chen (2007) and Ito (2010) use slope of yield curve and volatility. They calculate volatility of 2-year US Treasury notes using the EGARCH model.

\section{Data}

About 45 months of daily data, from January 14, 2009 to September 5, 2012, were chosen. These data are quoted from the Federal Reserve Statistical Release (H.15). S\&P downgraded the rating of Greek government bonds to A- on 
January 14, 2009, giving the reason that Greece's fiscal deficit would worsen amid the downward trend of the global economy. The ECB (European Central Bank) introduced OMT (Outright Monetary Transaction) on September 6, 2013. During the sample period, on February 27, 2012, S\&P downgraded the rating of Greek government bonds to SD (Selective Default).

\subsection{US Interest Rate Swap Spread}

US interest rate swap rate minus US government bond yield in the corresponding maturity is defined as swap spread. SS2 is 2-year swap spread. SS5 is 5-year swap spread. SS10 is 10- year swap spread. The descriptive statistics of swap spreads in each sample period are provided in Table 1. The movements of swap spreads in 2-years and 10-years for the whole sample period are shown in Figure 1.

\begin{tabular}{cccccc}
\multicolumn{6}{l}{ Table 1.Descriptive statistics of swap spreads } \\
\hline Variable & Average & SD & Min & Max & Median \\
\hline SS2 & 0.307 & 0.132 & 0.080 & 0.850 & 0.280 \\
SS5 & 0.310 & 0.125 & 0.030 & 1.030 & 0.290 \\
SS10 & 0.111 & 0.084 & -0.130 & 0.690 & 0.110 \\
\hline
\end{tabular}

Notes: $\mathrm{SS} 2=2$ - year swap spread, SS5 $=5$-year swap soread, $\mathrm{SS} 10=10$ - year swap spread

\subsection{Determinants of Swap Spread}

\subsubsection{Liquidity Premium}

Liquidity premium is defined as TED spread between the 6-month Eurodollar rate and the 6 month TB rate.

\subsubsection{Default Risk}

Default risk is defined as the yield spread between corporate bonds and 10-year US Treasury note yields. Corporate bond spread is considered to represent default risk. Moody's seasoned Aaa corporate bond is used. According to Moody's Investors Service, Aaa corporate bonds are judged to be of the highest quality, with minimal credit risk.



\subsubsection{Slope of Yield Curve}

Slope of yield curve is defined as the differential between 2- and 10-year US Treasury note yields, as in Huang and Chen (2007) and Ito (2010). 


\subsubsection{Volatility}

Yield volatility calculated by the EGARCH model is defined as volatility2. The 2-year US Treasury note yield is used for the calculation as in Huang and Chen (2007) and Ito (2010).

The descriptive statistics of the determinants of swap spreads in each sample period are provided in Table 2.

Table 2.Descriptive statistics of determinats of swap spreads

\begin{tabular}{cccccc}
\hline Variable & Average & SD & Min & Max & Median \\
\hline AAA & 1.875 & 0.267 & 1.390 & 3.000 & 1.820 \\
SLOPE & 2.236 & 0.465 & 1.210 & 2.910 & 2.370 \\
TED & 0.654 & 0.463 & 0.180 & 2.200 & 0.490 \\
VOLA & 0.035 & 0.016 & 0.010 & 0.114 & 0.035 \\
\hline
\end{tabular}

Notes $: \mathrm{AAA}=\mathrm{Aaa}$ corporate bond spread, $\mathrm{TED}=\mathrm{TED}$ Spread,

SLOPE $=$ Slope of yield curve, VOLA $=$ Volatility

\section{Framework of Analysis and Result}

This section indicates how to analyze the determinants of interest rate swap spread. First, OLS is used to estimate equation (4). The serial correlations and heteroscedasticity of $\varepsilon_{t}$ are adjusted by the method of Newey and West (1987). Twelve lag periods are used. The analysis for each sample period is conducted. The results are shown in Table3.

$$
\text { spread }_{t}=\alpha+\beta_{1} A A A_{t}+\beta_{2} S L O P E_{t}+\beta_{3} T E D_{t}+\beta_{4} V O L A_{t}+\varepsilon_{t}
$$

$\mathrm{AAA}=$ Aaa corporate bond spread; $\mathrm{SLOPE}=$ slope of yield curve;

TED = TED spread; VOLA = volatility.

As for Aaa corporate bond spread, the negative coefficient of 2-year spread is significant at the $10 \%$ level. The positive coefficients of 5 - and 10 -year spreads are significant at $10 \%$ and $5 \%$ levels respectively. This means that swap spreads of 5- and 10-years incorporate default risk in accordance with the theory. This point is totally different from that proposed by Ito (2010), which analyzed the determinants of swap spreads during the period of global financial crisis stemming from subprime loan problem in US.

As for slope, the negative coefficients of 2- and 10-year spreads are significant at the $5 \%$ and $1 \%$ levels, respectively. The fixed payer (floating receiver) is exposed to higher counterparty risk due to higher default risk exposure associated with the higher future floating payments because the yield curve is upward sloping, as mentioned in Alworth (1993). A lower fixed swap rate will compensate for this increased risk. This result is the same as Ito (2010). As for TED spread, the positive coefficients of 2- and 5-year spreads are significant at the $1 \%$ level. This fact indicates that the market participants paid attention to liquidity premiums only in short and mid- term swaps. This point is also similar to Ito (2010).

Table 3.Result of regression analysis

\begin{tabular}{cccccccc}
\hline & $\alpha$ & $\beta 1$ (AAA) & $\beta 2$ (SLOPE) & $\beta 3$ (TED) & $\beta 4$ (VOLA) & $\mathrm{R}^{2}$ & SER \\
\hline SS2 & 0.375 & -0.069 & -0.058 & 0.242 & 0.908 & 0.720 & 0.070 \\
& $(0.048)$ & $(-1.677)^{*}$ & $(-2.298)^{* *}$ & $(8.728)^{* * *}$ & $(1.384)$ & & \\
SS5 & 0.103 & 0.055 & -0.029 & 0.176 & 1.536 & 0.728 & 0.066 \\
& $(-1.326)$ & $(1.884)^{*}$ & $(0.133)$ & $(8.635)^{* * *}$ & $(2.830)^{* * *}$ & & \\
SS10 & 0.050 & 0.082 & -0.084 & -0.023 & 3.122 & 0.295 & 0.084 \\
& $(0.641)^{* * *}$ & $(2.047)^{* *}$ & $(-4.710)^{* * *}$ & $(-0.781)$ & $(4.871)^{* * *}$ & & \\
\hline
\end{tabular}

Notes: Values in the parenthesis are $\mathrm{t}$ statistics.

$* * *, * *, *$ indicates significance at $1 \%, 5 \%$ and $10 \%$ levels respectively.

The serial correlation and heteroscedasticity of errors are adjusted by the method by Newey and West (1987).

$\mathrm{AAA}=\mathrm{Aaa}$ corporate bond spread, $\mathrm{SLOPE}=$ Slope of $\mathrm{yield}$ curve, $\mathrm{TED}=\mathrm{TED}$ spread, $\mathrm{VOLA}=$ Volatility

As for volatility, the positive coefficients of 5 - and 10-year spreads are significant at the $1 \%$ level. The market participants were uncertain as to the future monetary policy of the FRB (Federal Reserve Board) and speculation on the

${ }^{2}$ See Nelson (1991) for the EGARCH model. 
path of monetary policy thus caused more volatility in the market. This volatility can be a positive determinant of US swap spreads in the period of financial crisis. This point is basically same as Ito (2010).

\section{Concluding Remarks}

This paper analyzes US interest rate swap spreads in relation to the sovereign crisis of the Euro zone. The results reveal that swap spreads of 5- and 10-years incorporate default risk positively in accordance with the theory. The function of price discovery in the market worked in spite of financial shocks caused by the sovereign crisis of the Euro zone. The impact of default risk is totally different to that proposed by Ito (2010), which analyzed the period of global financial crisis stemming from subprime loan problem in the US. According to Ito (2010), the default risk is negatively incorporated in the period of financial crisis. This is mainly due to the difference of magnitude of the two crises. The impact of the sovereign crisis of the Euro zone was not as great as the previous crisis stemming from US sub-prime loan.

On the other hand, the impacts of slope, TED spread, and volatility are similar to those found by lto (2010). Steeper yield curve causes narrower swap spreads of 2- and 10-years. When liquidity gets tighter in the money market, swap spreads of 2- and 5-years get wider. The impact is greater in magnitude in 2 -year swap spreads. Higher volatility causes the widening of 5- and 10-year swap spreads. This is mainly because the market participants were uncertain about the FRB's future monetary policy. The FOMC (Federal Open Market Committee) decided to increase its purchase of assets from the markets on September 13, 20123, 8 days after the sample period of this paper ended.

\section{Acknowledgement}

The comments by reviewers are highly appreciated. This paper is supported financially by Grant-in-Aid for Research Project from Institute of Humanities, Social Sciences and Education, Niigata University.

\section{References}

Alworth, J.S. (1993). The valuation of US dollar interest rate swaps. BIS Economic Papers, No. 35.

Bank for International Settlements (2012). OTC derivatives market activity in the second half of 2012.

Brown,K., Harlow,W. and Smith,D.J. (1994). An empirical analysis of interest rate swap spreads. Journal of Fixed Income, March, 61-78.

Cossin,D. and Pirotte,H. (1997). Swap credit risk : an empirical investigation on transaction data. Journal of Banking \& Finance, 21, 1351-1373.

Duffie,D. and Huang,M. (1996). Swap rates and credit quality. Journal of Finance, 51, 921-949.

Fehle,F. (2003). The components of interest rate swap spreads: theory and international evidence. Journal of Futures Markets, 23 , $347-387$.

Huang,Y. and Chen,C.R. (2007). The effect of Fed monetary policy regimes on the US interest rate swap spreads. Review of Financial Economics, 16, 375-399.

Ito,T. (2010). Global financial crisis and US interest rate swap spreads. Applied Financial Economics, 20, 37-43.

Lang,L.H.P., Lizenberger,R.H., and Liu,L.A. (1998). Determinants of interest rate swap spreads. Journal of Banking and Finance,22,1507-1532.

Lekkos,I. and Milas,C. (2001). Identifying the factors that affect interest rate swap spreads: some evidence from the United States and the United Kingdom. Journal of Futures Markets, 21, 737-768.

Minton,B.A. (1997). An empirical examination of basic valuation models for plain vanilla U.S. interest rate swaps. Journal of Financial Economics, 44, 251-277.

Nelson,D.(1991). Conditional heteroskedasticity in asset returns: A new approach. Econometrica, 59, 347-70.

Newey,W.K. and West,K.D.(1987). Simple, positive semi-definite, heteroskedasticity and autocorrelation consistent covariance matrix. Econometrica, 55,703-708.

Sorensen,E. and Bollier,T.F.(1994). Interest rate swap default risk. Financial Analysts Journal, 50, May-June, 23-33.

Sun,T., Sundaresan, S. and Wang, C. (1993), 'Interest rate swaps : an empirical investigation', Journal of Financial Economics, 34, 7799.

\footnotetext{
${ }^{3}$ To support a stronger economic recovery and to help ensure that inflation, over time, is at the rate most consistent with its dual mandate, the Committee agreed today to increase policy accommodation by purchasing additional agency mortgage-backed securities at a pace of $\$ 40$ billion per month.
} 